\title{
Subtle radical moves in scientific publishing
}

\begin{abstract}
Over the past 15 years, alternative payment models for the dissemination of research such as author-pays or author's funder-pays have emerged [...] Electronic products, such as ScienceDirect, Scopus and ClinicalKey, are generally sold direct to customers through a dedicated sales force [...] Reference and educational content is sold directly to institutions and individuals [...] We expect another year of modest underlying revenue growth, with underlying operating profit growth continuing to exceed underlying revenue growth. (RELX 2017, 16-17)
\end{abstract}

The market-driven academic publishing business seems to have gotten a stranglehold on scholars. The dominant publishing houses - known as the 'Big Five'1 - play with us as they please. Their power has grown exponentially. In the early 90 s, their share of social science journal articles was around 15\% while now the number is close to $70 \%$, as the splendid analysis by Larivière, Haustein and Mongeon (2015) shows. The companies have extremely good profit margins, estimated to be generally around 20-30\% (Padula et al. 2017). The largest of the Big Five, with revenues of 2,320 million pounds in 2016, makes no effort to hide what it stakes in scientific publishing. ${ }^{2}$ In an annual report, the company proudly presents its success as follows:

Our largest markets remained resilient during 2016 and we continued to execute against our strategic priorities aimed at achieving more predictable revenues, a higher growth profile and improving returns. As a result, growth of underlying revenues gradually improved to $4 \%$ and underlying adjusted operating profits grew $6 \%$, as we continued to grow revenues ahead of costs (RELX 2017, 3).

These profits are largely generated by the scholarly community. We deliver the substance to the products of the commercial publishers, run a major part of their production as editors, and provide the quality assurance to the processes and end products as peer reviewers. The publishing houses would have nothing to sell without us, yet we find ourselves caught in this production. We submit, edit and provide reviews, thus contributing to the ever-growing hill, like worker-ants. What is more, we also pay for the publications that we produce with them, not once but multiple times. Large part of our research is publically funded, which means that governments make huge financial investments in the production of academic publications. Then subscriptions to the journals we publish in are sold to our libraries, often with long and unnegotiable embargos protecting the content from being too easily accessible. Thereafter the papers are offered for sale to research funders and institutions, as well as individual researchers, who wish to make the results of their research accessible soon after publication through what is called green and golden open access. In some journals this author-pays or author's funder-pays payment model, as named by the RELX company, is the primary way to get published.

The institutional, often nationally legitimated, journal ranking systems strongly reinforce this development. Respected journals grow ever more important as everyone seeks to publish in them to gain academic merit and acknowledgement, and concurrently, other journals become less and less worthy as publishing in them does not equally promote scholarly careers. In addition to esteem, career development is about bread and butter, as so many of us has witnessed in the past years. Thus, scholars keep on carrying straws to the heap, as the Finnish saying goes.

Both young and senior scholars are at pains with the situation. When discussing the topic with colleagues in events such as the Annual Meeting of the American Association of Geographers (AAG), you often end up first lamenting the corrupt system but then jointly admitting that playing along is the only option. "I just saw your paper published in the journal $X$, congratulations!" is a common greeting at the corridors, usually referring to one of the journals published by the Big Five. This genuine joy is an important part of the conduct of conduct that keeps the wheels rolling, to use a Foucauldian expression.

Since I started to edit Fennia a year ago, I have become increasingly aware of this problematic in general but also personally. Am I asking colleagues to sacrifice their careers when inviting them to write in the journal, especially the young scholars who perhaps benefit the most from the journal's open access policy? Do I act against my institution's aims by publishing in journals that do not rank 
high in the Finnish journal assessment system, and how will that effect on our research group when assessed with reference to this ranking? Is there any credibility in my critique, as my own work can also be found in the Big Five journals where I regularly publish along with most other geographers?

In my despair, I turned to Michel de Certeau, whose work has been vastly influential in geography. In his book Arts de Faire, de Certeau (1984, xiv-xv) describes "a multitude of 'tactics' [...] the clandestine forms taken by the dispersed, tactical, and makeshift creativity of groups or individuals already caught in the nets of 'discipline'." How could we mobilise the "networks of an antidiscipline" by the means of the weak in academic publishing where the giants have so skilfully learned to discipline individual scholars, scholarly communities, academic institutions, and governments?

It may be the fullness and extensiveness of the problem that tricks us into seeking big answers and thus playing the big game with very little means. Perhaps small steps should rather be taken to generate new small games that are harder to rule, from outside and from above. Could the radical publishing ethos emerge through subtle moves instead of solemn manifestations? Can we find ways to do little things that may gradually change the climate of academic publishing and possibly, in the long term, succeed to change the rules by which this business is run?

Finding space for such tactical moves requires a closer look at publication processes, and to this end, let me portray a typical trajectory through which a manuscript is processed in a scholarly journal:

1) The manuscript is submitted by the author(s)

2) The manuscript is assessed for fit and basic quality by the editor(s)

3) If seen fit, the responsible editor starts to seek for suitable peer reviewers

4) The manuscript is sent out for external review

5) The reviewers provide comments to the author(s) and the editor(s)

6) A preliminary decision is made by the editor(s), based on the review reports

7) The author(s) receive the decision and, if revisions are requested, decides whether or not to revise the manuscript along the requested lines; in the case of rejection, the process ends in this journal

8) The author(s) resubmit the revised manuscript, sometimes including language editing, together with the response letter

9) The revised version of the manuscript and the response letter are assessed by the editor(s)

10) The manuscript is possibly sent out to external review, for the same or new reviewers

11) The reviewers provide comments on the revised manuscript

12) A final decision is typically made at this point by the editor(s), yet a second revision and third peer review round are also possible (repeating steps 7-12)

13) The author(s) receive the decision and, if minor revisions are requested, revise the manuscript; in the case of rejection, the process ends in this journal

14) The author(s) resubmit the finalised manuscript, perhaps together with a response letter

15) The manuscript is accepted for publication by the editor(s)

16) The accepted manuscript is sent for copyediting, and possibly language editing

17) The author(s) receive the proofs for technical corrections

18) The proofs are assessed and accepted by the copyeditor, perhaps requiring further rounds of corrections

19) The paper is published online

20) The paper is published in an issue.

Even this minimalistic description shows that the process of publishing a referee journal article contains a significant amount of academic 'volunteer work' by authors, editors, and reviewers. It also reveals stages where publication processes may lengthen or become complicated, for various reasons. These steps, not easily controllable by the publisher, may be the most opportune moments for influencing the system.

The experience I have gained in journal publishing - as author, reviewer, editor and publisher points towards peer reviewing as a particularly critical element in the publication process. Journals are reliant on external assessment, without which they would be publishing merely learned texts without quality control by peers. This practice relies on a large scientific community with scholars ready to 
provide their expertise for the use of the publishers without payment. Even if each commitment to review a manuscript is relatively small, the work tends to pile up: trusted scholars with up-to-date expertise on certain topics are generally requested for reviews. As the merits gained from peer reviewing are minimal, the possibility to influence the research field remains the greatest award from this work. Compared to authors and editors, reviewers hence have much less at stake in an individual publication process.

Herein, I suggest, lies one possibility for radical academic agency. By committing deliberately to peer reviewing in alternative journals, scholarly communities could generate an asset that the Big Five and other commercial publishers cannot easily conquest. This of course requires collaboration from scholars in their interchanging positions as reviewers, authors, editors and publishers, and perhaps prioritising alternative journals over commercial ones when committing to reviewing to avoid a growing workload.

Peer reviewing consists of a number of elements that can be enhanced. Publishers may improve their policies and practices, to support the work of reviewers and reward them for their work in one way or another. Editors have many opportunities to ensure a good quality peer review before, after and during the process. Frustrating review work can be reduced by making desk rejections and asking for technical corrections prior to the review process; thus, only carefully written papers with good potential are sent out for review. Taking an active stance between the reviewers and the authors, instead of just passing on review reports that sometimes are perplexingly contradictory or unjust to the manuscript, warrants that the reviews serve the process adequately. Some reviews may also be invited to the journal as commentaries to published articles. Authors, on their behalf, can try to make the best use of the reviews and respond to them in a careful manner, including discussion about the reviews with the editors. And what about the key actors of the process, the reviewers? As I see it, simply providing justified comments in a respectful manner, even when you do not like or agree with the paper, makes a good review report. This is sometimes achieved better in an open review process where the reviewer and the author engage in a dialogue as persons with names and faces - a procedure that journals can actively encourage.

Those of us regularly writing, editing and reviewing know that what I have suggested above requires special effort and does not always succeed despite the good intentions. However, I believe that this work could pay back. If we are able to generate fast, good quality review processes by working together in alternative journals, this may lead to publishing our work within months rather than years, openly accessible from day one. Moreover, retaining all rights to published work - as requested by the Creative Commons and many genuinely open access journals - provides the authors the option of making their work visible and accessible in a number of other venues as well. The combination of ethical open access policy and community-driven peer reviewing could provide one radical opening through which to break out subtly from the commercial domination that we are collectively experiencing.

These thoughts are not mine alone. They have developed in national and international collaboration with colleagues and institutional actors, whom I wish to thank for sharing these concerns and taking some of these ideas further with me. In Finland, we are currently seeking new publishing policies, practices and ethics, first, in the Kotilava project led by the Federation of Finnish Learned Societies and the National Library and, second, in the Julkea! project bringing together three scientific societies and academic journals. Internationally, Fennia is engaged in a network of alternative geography journals. We convened in April at the Boston AAG conference in a panel session introducing and debating the non-commercial alternatives in journal publishing in geography. It was organized and chaired by Simon Batterbury who edits the Journal of Political Ecology, with panelists from the journals Human Geography (Dick Peet, John Finn), ACME (Simon Springer, Lawrence Berg absent) and Fennia (myself). Another panel will take place in the forthcoming Nordic Geographers Meeting (NGM) in Stockholm, organised by Fennia and involving an international panel of distinguished scholars: Stuart Aitken, Marianne Blidon, Sara Fregonese, Jonathan Metzger, Katharyne Mitchell, Pierre Mounier and Phil Steinberg. This panel will focus on the challenges of publishing in the Anglo-centred academy, and welcomes everyone from the conference to participate in discussions on publishing also more broadly. Both discussions will be published in Fennia's new publication section Reflections later this year, which 
we hope will continue the discussion on academic publishing within and beyond geography. Additional discussion pieces may be suggested to the responsible editor lames Riding, who joined the editorial team this spring.

This issue of Fennia includes four research articles, a Reflections series based on the keynote lecture by Henk van Houtum at the 2016 Annual Meeting of Finnish Geographers in Joensuu, and one book review. It launches Reflections as a new publication format that, we hope, will enliven discussions on topical and critical issues in geography and neighbouring research areas. It is dedicated to publishing short critical reflections on any aspect of the discipline of geography, offering a space for empirically grounded as well as theoretically informed research speaking to contemporary geographic concerns. We encourage submissions in alternative, unconventional formats, and pieces that emerge from collaborations between scholars and creative practitioners for instance. Moreover, this issue begins the series of Fennia lectures that will be organised by and published in the journal regularly, with invited commentaries.

In addition to the new publication formats, Fennia has accomplished several technical renewals during the spring. We have joint in the new journal management and publishing service of the Federation of Finnish Learned Societies (Journal.fi). This has meant moving to a new website (fennia. journal.fi) and taking up the OJS 3 open source software from the Public Knowledge Project. On top of these major technical amendments, our managing editor Hanna Salo has updated the layout of the publication and we have revised our author guidelines. The editorial team hopes that this all will make Fennia better accessible to broad audiences and smoothen the publication processes between authors, reviewers, and editors.

Please enjoy and circulate broadly these fully open access pieces of work, and do not hesitate to contact the editors with your novel and even radical publication ideas.

KIRSI PAULIINA KALLIO

FENNIA EDITOR-IN-CHIEF

\section{NOTES}

1 The names of these publishers are purposefully not mentioned in this editorial.

2 This includes services related to "scientific, technical and medical markets by organising the review, editing and disseminating of primary research, reference and professional education content, as well as by providing a range of database and decision tools".

\section{REFERENCES}

de Certeau, M. (1984) The practice of everyday life. University of California Press, Berkeley.

Larivière, V., Haustein, S. \& Mongeon, P. (2015) The oligopoly of academic publishers in the digital era. PLOS ONE 10(6) e0127502. https://doi.org/10.1371/journal.pone.0127502

Padula, D., Brembs, B., Harnad, S., Herb, U., Missingham, R., Morgan, D. \& Ortbal, J. (2017) Democratizing academic journals: technology, services, and open access. White paper, issued March 2017. <https://t. co/fjAZNUZDCU 3.5.2017> 03.05.2017

RELX (2017) RELX group annual report 2016. RELX group company reports. RELX Group. <http://www. re/X. com/investorcentre/reports\%202007/Documents/2016/relxgroup ar 2016.pdf> 03.05.2017. 